\title{
Declines of Bighorn Sheep, Ovis canadensis, on Deteriorating Winter Range in Jasper National Park, Alberta, 1981-2010
}

\author{
DiCK DEKKER \\ 3819-112 A Street NW, Edmonton, Alberta T6J 1K4 Canada; email: ddekker1@telus.net
}

Dekker, Dick. 2009. Declines of Bighorn Sheep, Ovis canadensis, on deteriorating winter range in Jasper National Park, Alberta, 1981-2010. Canadian Field-Naturalist 123(2): 157-164.

\begin{abstract}
Bighorn Sheep (Ovis canadensis) wintering in the lower Athabasca River valley of Jasper National Park, Alberta, were monitored from 1981 to 2010 by recording maximum band sizes per annum on two traditional but separate sheep ranges. In study area \#1, the ram band declined significantly from a 20-year mean of 18 in the period 1981-2001 to a 5-year mean of 11 in the period 2001-2006, with a slight recovery in 2006-2010. Ewes in area \#1 dwindled from a mean of 20 in the period 1981-1995 to zero in the period 1995-2010. In area \#2, the ewe band dropped significantly from a mean of 40 in the period 1981-2001 to 24 in the period 2001-2010. The declines in area \#1 coincided with an invasion of Russian Thistle (Salsola kali). Range conditions in area \#2 deteriorated following four years with lower than average annual precipitation. The mean lamb:ewe ratio in area $\# 2$, pooled for 29 years, was $22: 100(n=646)$. The sheep were protected from hunting, but were subject to a full range of indigenous carnivores. However, predation did not appear to be the primary cause of the declines, nor was competition for forage with American Elk (Cervus elaphus).
\end{abstract}

Key Words: Bighorn Sheep, Ovis canadensis, winter range, predation, Jasper National Park, Alberta.

Alberta's population of Bighorn Sheep (Ovis canadensis) was estimated at 11500 , which is roughly $25 \%$ of the North American total (Wishart 1999). The province has been the setting of several intensive research projects, including the capture and tagging of entire local populations (Festa-Bianchet 1991; Jorgenson et al. 1993; Festa-Bianchet et al. 1996; Jorgenson et al. 1997; Portier et al. 1998; Wishart et al. 1998). This research resulted in the accumulation of a vast amount of data on density-dependent growth rates, productivity, individual survival, and disease. Sexual segregation of mature rams and ewes was found to be based on differing nutritional demands and time budgets (Ruckstuhl 1998), and sexual segregation was identified as an important adaptive phenomenon in the ecology and distribution of bighorns that affects foraging efficiency, movement patterns, and predator avoidance (Geist 1971; Ruckstuhl and Festa-Bianchet 2001).

Risk of predation by cursorial carnivores forces mountain-dwelling sheep to stay close to steep escape terrain, where forage may be in limited supply (Murie 1944). Although the anti-predator strategies of bighorns are quite effective against canids, they provide no security from ambush predators, such as the Cougar (Puma concolor). Sheep mortality caused by Cougars has been studied in Alberta and elsewhere (Ross et al. 1997; Rominger et al. 2004). Based on stochastic predation events at two sites in Alberta, Festa-Bianchet et al. (2006) hypothesized that the viability of small, isolated sheep populations is at risk and that these populations could face serious decline or even local extinction if individual Cougars specialize on sheep prey. Festa-Bianchet et al. (2006) further suggested that "predator-prey equilibria may only exist at large geographical and temporal scales" and equilibrium is unlikely in view of increasing habitat fragmentation.

The purpose of the present study was the long-term monitoring of a localized Bighorn Sheep population wintering in Jasper National Park of Canada, which contains the largest contiguous and protected bighorn range in North America today. The sheep are subject to predation by a full complement of indigenous carnivores, including Wolves (Canis lupus), Coyotes (Canis latrans), and Cougars. Unlike other locations in Alberta, the study area has not been subject to hunting or known outbreaks of contagious disease. Furthermore, and again unlike other Alberta populations, the sheep in Jasper National Park have not been studied closely since the 1970s.

During the 1940s and 1960s, Canadian Wildlife Service biologists working in the park repeatedly argued that overpopulation by American Elk (Cervus elaphus) was having a serious negative impact on Bighorn Sheep and that the problem was being compounded by the recent return of the Wolf (Cowan 1947). Stelfox (1978) warned that the bighorn population of Athabasca valley in the park was at risk of a major die-off because of competition from Elk for forage on shared and severely overgrazed winter range. However, conditions improved after Elk numbers fell steeply in the 1970 s due to a series of severe winters with record snow coupled with a surge in Wolf numbers (Dekker et al. 1995).

In addition to presenting sheep numbers over 29 consecutive years, this study reports on (1) carnivore predation on sheep, (2) local Elk numbers and the 
potential for competition for forage between Elk and Bighorn Sheep, and (3) deterioration of the range due to a noxious weed infestation and a period of drought. Long-term naturalistic field studies such as this are crucial to provide the data and insights required to understand the impact of climate change on the living world (Jensen 2004). They are all the more important today because our last remaining wild places are continuing to be destroyed at an unprecedented rate (Schmidly 2005).

\section{Study Area and Methods}

Jasper National Park is $10880 \mathrm{~km}^{2}$ in size and is situated in west-central Alberta between $52^{\circ} 29^{\prime}$ and $52^{\circ} 08^{\prime}$ north latitude. Elevations range from a peak of $3747 \mathrm{~m}$ in the west to a low of $990 \mathrm{~m}$ in the east. The three main ecoregions are alpine, subalpine, and montane. Of these, the montane is the smallest in extent but of critical importance, containing the richest diversity of flora and fauna and providing vital wintering range for the park's large mammals, which include seven species of ungulates. For a detailed description of the park's habitats and wildlife inventory, see Soper (1970) or Holroyd and VanTighem (1983).

During the past 150 years, numbers of Bighorn Sheep have fluctuated markedly in the national parks in the Rocky Mountains in Alberta, from near extirpation due to hunting in the 1800 s to an apparent overpopulation after severe Wolf control campaigns in the 1950s (Stelfox 1971; Gunson 1992). However, in response to protective measures, the large mammal system of Jasper National Park eventually recovered, and the period from 1967 to 1987 appears to have been quite stable. An aerial survey flown along 20 mountain ranges in January 1967 produced a total estimate of 2011 sheep (Stelfox 1971). Twenty years later, park wardens flew the same ranges and tallied 2278 sheep (Wes Bradford, personal communication.).

The Bighorn Sheep is the most numerous species of ungulate in Jasper National Park. Occurring mainly in the front ranges, sheep reach their highest concentrations in the lower Athabasca River valley (Cowan 1947; Soper 1970; Holroyd and VanTighem 1983). Varying in height and aspect, the east-facing slope of the Athabasca valley rises to $200-300 \mathrm{~m}$ above the montane bottomlands and is characterized by a mosaic of coniferous forest, open slopes, and rocky outcrops. From October to April and during part of the summer months each year, sheep occur all along this $20-\mathrm{km}$ escarpment, from the Snaring River to the park's east gate, and possibly well beyond. However, during winter, they are concentrated at traditional points that include steep escape terrain as well as exposed grassy slopes where frequent Chinook winds reduce snow cover. Two such areas were selected for this study. They are about $2 \mathrm{~km}$ apart and both contain roughly 100 ha of open, grassy terrain. Site \#1 is called Ram Pasture and site \#2 the Canyon. At the base of both hillside pastures are limestone cliffs 30-50 m high.

The methodology in this study was designed to cause a minimum of human disturbance. The study area was a relatively remote corner of the park accessed on foot. At the Ram Pasture, sheep were observed from the wooded upper ridge, which gave a clear view of the grassy slopes below. The sheep were not shy and tolerated a close approach. The Canyon is a steep, south-facing slope that can be viewed from a hillside bluff on the opposite side of the Snake Indian River valley. The same hill served as a lookout point from which the adjacent river flats and semi-open montane meadows were scanned. All mammals seen were recorded in a diary and entered into the logbook of the district's patrol cabin.

Between mid-October and the end of March from the winter of 1981-1982 to 2009-2010, the study area was visited 9-12 times each year. Each visit included one to three overnight stays. Over 29 years of this 30year period (no data were collected in 2007-2008), the accumulated number of full days afield was 627 . During each visit, area \#1 was walked at least once. Area \#2 was checked twice a day, in early morning and again in the evening. Each check involved one hour of scanning the canyon and the flats through binoculars. In total, the Canyon viewpoint was manned approximately 1300 times over the study period. For each year, records were kept of the maximum number of sheep in the Canyon band-including ewes, lambs and yearlings - while rams with horns larger than those of mature ewes were deleted from the total. For $100 \%$ reliability, classified counts were restricted to opportunities when all members of a discrete group, no matter its size, were in good view. The lamb:ewe ratios were pooled per year irrespective of possible duplication, and the accumulated total for the 29 years was tabulated per month from October to March.

The study area is a major wintering range for Elk (Dekker et al. 1995). The maximum observed size of the local Elk cow herd was used as a parameter of population size for each winter. Other ungulates common in the study area are Mule Deer (Odocoileus hemionus) and White-tailed Deer (Odocoileus virginianus), which were counted separately but not reported here. The local Wolf population was assessed on the numeric size of the largest pack seen, and Coyote presence was based on sightings per field day. Most of these data have previously been published (Dekker 1989, 1998) and were included in (unpublished) reports for the Jasper National Park warden office (Dekker 2001*, 2008*).

In addition to sheep numbers, this study includes cursory information on range conditions on the Ram Pasture, the Canyon, and the adjacent montane meadows. Annual precipitation totals were obtained from Environment Canada for recording stations closest to the study area (East Gate and Jasper Warden Station). Some values were compared statistically with a chi- 


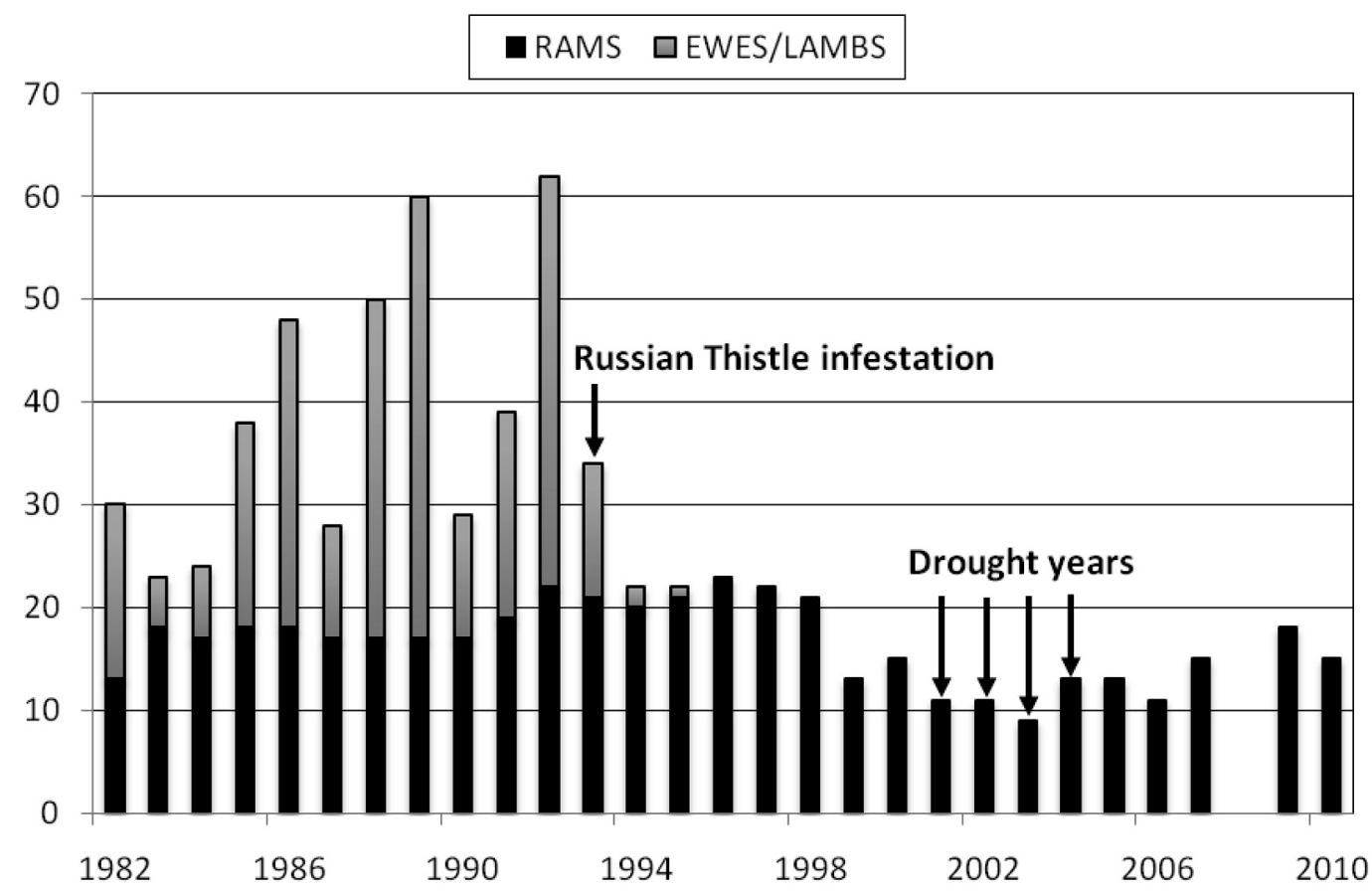

FIGURE 1. Maximum band sizes per annum of two segregated groups of Bighorn Sheep at the Ram Pasture wintering range in Jasper National Park, Alberta. The disappearance of the nursery band coincided with a serious outbreak of Russian Thistle (data for 2008 were not available).

squared contingency test and a Student $t$-test on sample mean differences.

\section{Results}

Study area \#1 (the Ram Pasture) is the traditional winter range for a group of mature rams. During October, the odd ram might be present but he would subsequently leave again in advance of the November mating season. By mid-December, rams had begun to arrive singly and they eventually assembled into a cohesive band that stayed well beyond the end of March. The maximum size of the ram band changed little from year to year, and the annual mean remained at 18 over 20 winters (Table 1). After 2001, the number of rams declined significantly to a 5 -year mean of 11 $(t=6.28, P<0.001)$ but recovered slightly in the years 2007-2010. Prior to 1995, the Ram Pasture was also used by a nursery band of ewes, yearlings, and lambs (the ewe band). The maximum size of this band fluctuated between years (Table 1). From the winter of 1981-1982 to the winter of 1992-1993, the annual mean size of the ewe band was 23, but in the winter of 19941995 , only two ewes were seen, and the following winter only one. From 1995 to 2010, not a single ewe, yearling, or lamb was recorded on the Ram Pasture (Figure $1)$.
Study area \#2 (the Canyon) was frequented by one or more mature rams during the fall mating season, but rarely after December. On occasion, rams were observed traveling from the Canyon to Ram Pasture; this involved traversing several narrow belts of forest. Groups of ewes, yearlings, and lambs could be seen on the Canyon slopes at any time of the year. From October to March, the maximum size of the band varied greatly from day to day as well as from year to year, but the 5-year running mean stayed roughly the same during the first 20 years at 40 until it dropped significantly to 24 in the period 2001-2010 $(t=1.83$, $P<0.01)$. During the last two years of the study, the ewe band declined to one-third of its former size (Table 1).

The lamb:ewe ratio on the Ram Pasture (over the 12 winters that the local ewe band persisted) was 24:100 $(n=128)$, nearly identical to the $22: 100(n=791)$ recorded at the Canyon over the 30 years of the study (Table 2). The accumulated figures for October were 30:100 $(n=265)$, higher than the 19:100 for March $(n=225)$, but the difference was not significant $(P>0.15)$.

The local Elk herd was monitored concurrently with the sheep census. Here, too, the sexes were segregated, with mature Elk bulls widely scattered and 
TABLE 1. Maximum recorded band sizes per year and 5-year running means of the Bighorn Sheep population at two adjacent but discrete wintering ranges in the lower Athabasca River valley of Jasper National Park, Alberta, 1981-2010 (data for 2008 were not available).

\begin{tabular}{|c|c|c|c|}
\hline \multirow[b]{2}{*}{ Year (winter) } & \multicolumn{2}{|c|}{ Study site \#1 } & \multirow{2}{*}{$\begin{array}{c}\text { Study site \#2 } \\
\text { Ewe band }\end{array}$} \\
\hline & Ram band & Ewe band & \\
\hline 1981-1982 & 13 & 17 & 29 \\
\hline 1982-1983 & 18 & 5 & 75 \\
\hline 1983-1984 & - & - & 25 \\
\hline 1984-1985 & 18 & 20 & 31 \\
\hline 1985-1986 & 18 & 30 & 23 \\
\hline Mean & 16.8 & 18.0 & 36.6 \\
\hline 1986-1987 & - & - & 54 \\
\hline 1987-1988 & 17 & 33 & 77 \\
\hline 1988-1989 & 17 & 43 & 38 \\
\hline 1989-1990 & 17 & 12 & 40 \\
\hline 1990-1991 & 19 & 20 & 21 \\
\hline Mean & 17.5 & 27.0 & 46.0 \\
\hline 1991-1992 & 22 & 40 & 54 \\
\hline 1992-1993 & 21 & 13 & 31 \\
\hline 1993-1994 & 20 & 2 & 26 \\
\hline 1994-1995 & 21 & 1 & 30 \\
\hline 1995-1996 & 23 & 0 & 45 \\
\hline Mean & 21.4 & 11.2 & 37.2 \\
\hline 1996-1997 & 22 & 0 & 26 \\
\hline 1997-1998 & 21 & 0 & 55 \\
\hline 1998-1999 & 13 & 0 & 61 \\
\hline $1999-2000$ & 15 & 0 & 24 \\
\hline 2000-2001 & 11 & 0 & 28 \\
\hline Mean & 16.4 & 0 & 38.8 \\
\hline 2001-2002 & 11 & 0 & 14 \\
\hline $2002-2003$ & 9 & 0 & 33 \\
\hline 2003-2004 & 13 & 0 & 27 \\
\hline 2004-2005 & 13 & 0 & 40 \\
\hline $2005-2006$ & 11 & 0 & 15 \\
\hline Mean & 11.4 & 0 & 25.8 \\
\hline $\begin{array}{l}2006-2007 \\
\text { (Not available) }\end{array}$ & 15 & 0 & 36 \\
\hline 2008-2009 & 18 & 0 & 14 \\
\hline 2009-2010 & 15 & 0 & 14 \\
\hline Mean & 16.0 & 0 & 21.3 \\
\hline
\end{tabular}

the cows staying together in one or two groups. The cow herd included calves as well as yearlings of both sexes. Its maximum size remained remarkably stable, with an annual mean of 49 animals during the first 20 years. In the period 2001-2010, the size of the cow herd dropped to a mean of 38 . However, the decline was not significant $(t=1.70, P<0.06)$.

As for the local predators, there is no information on the size of the Cougar population in Jasper National Park. During this study, one or more Cougars were tracked each winter and were seen on seven different occasions. Wolves were recorded, either by tracks or sightings, during all visits. Western Wolves show a wide spectrum of colour variants, from white to black, and packs are territorial (Dekker 1989, 1998). Repeat sightings of recognizable animals indicated that the study area was frequented by only one dominant pack.
TABLE 2. Lamb:ewe ratios for Bighorn Sheep by month, pooled for 29 consecutive years, at the Canyon wintering range in Jasper National Park, Alberta.

\begin{tabular}{lccc}
\hline \hline Month & Ewes & Lambs & Lambs/100 ewes \\
\hline October & 204 & 61 & 30 \\
November & 125 & 22 & 18 \\
December & 45 & 9 & 20 \\
January & 28 & 5 & 18 \\
February & 55 & 12 & 22 \\
March & 189 & 36 & 19 \\
Total & 646 & 145 & 22 \\
\hline \hline
\end{tabular}

However, during the winters of 1996-1997, 1997-1998, and 1998-1999, a second group was occasionally sighted, containing 9, 5, and 2 members, respectively. Between 1981 and 2001, the maximum size of the territorial pack ranged from 2 to 13 , with a mean of 7.8 . In the period 2001-2010, the mean dropped to 4.0. The decline was significant $(t=.81, P<0.01)$. The Coyote population also declined over the course of the study. Between 1981 and 2001, a total of 119 Coyotes was sighted over 542 observation days, averaging 0.2 Coyotes per day, but this dropped to 0.03 Coyotes per day in the period 2001-2010.

Weather data, obtained from Environment Canada, indicate that annual precipitation decreased from a 35-year mean of $569 \mathrm{~mm}$ in the period 1971-2006 to a mean of $430 \mathrm{~mm}$ in the period 2001-2004. These four years represented a major deviation from normal precipitation patterns, and the Student $t$-test showed a high degree of significance $(t=7.52, P<0.001)$. The last two years, 2008 and 2009, were again very dry, with 306 and $194 \mathrm{~mm}$ of annual precipitation, respectively, the lowest amounts recorded at Jasper since 1971.

\section{Discussion}

The decline of this bighorn population between 2001 and 2010 is all the more remarkable because of the population's stability during the previous 20 years. To explain the decline, by way of hypothesis, the various proximate factors that can negatively affect sheep dynamics, apart from disease, are (1) population density, (2) fecundity, (3) competition for forage from other grazers, (4) predation, and (5) poor habitat (Cowan 1947; Stelfox 1971; Geist 1971; Jorgenson et al. 1997; Festa-Bianchet et al. 2006).

Theoretically, bighorn herds have the potential to double their numbers in about three years, but that rate of increase cannot be reached on inadequate range (Wishart et al. 1998). To reduce the risk of predation, sheep confine themselves to islands of suitable habitat, which soon become overpopulated. This in turn leads to a reduction in pregnancy rates, stunted growth of yearlings, and poor lamb survival (Geist 1971). An indication that the bighorns in Jasper National Park were affected by one or more of the above limiting factors is their low lamb:ewe ratio. 


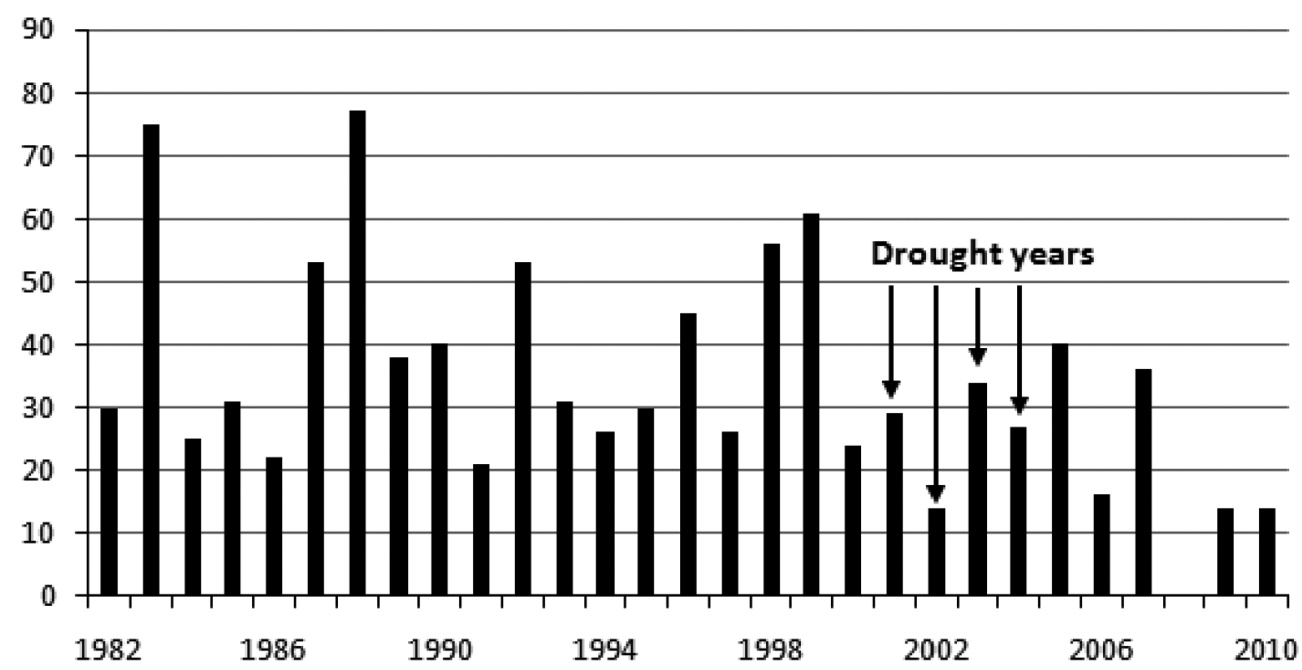

FIGURE 2. Maximum size per year of the Bighorn Sheep nursery band (including yearlings and lambs) at the Canyon wintering range, 1981-2010 (data for 2008 were not available). During the drought years of 2001-2004, the steep south-facing slope became practically denuded of forage plants.

Ratios reported by other researchers in Jasper National Park and Banff National Park of Canada, obtained from various localities and at various times of year, range from 15 to 51 lambs per 100 ewes (Holroyd and VanTighem 1983). For comparison with the results reported in this paper, the most relevant survey data, dating back to 1978-1979, are from the lower Athabasca valley in Jasper National Park. Monthly counts from October to March yielded an accumulated ratio of 31 lambs per 100 ewes. However, unlike the results of this study, those data did not include yearlings. If the yearlings, which were counted separately by Holroyd and VanTighem (1983), are added, the adjusted ratio is $27: 100$, which is still higher than the 29-year mean of 22:100 found in this study.

\section{Range competition from Elk}

There is no evidence to suggest that the decline in the sheep population may have been caused by competition with Elk for range. On the contrary, based on maximum herd sizes per annum, the Elk population changed very little between 1981 and 2001, until it too dropped during the drought of 2001-2004. The decline in Elk parallels the decline in sheep and points away from interspecific forage competition. Furthermore, the Elk grazed mainly on the flats, away from the hills where the sheep were. The underlying factor affecting the decline of both species simultaneously may well have been either one or both of the next two potentially limiting factors: predation and deterioration of the winter range.

\section{Predation}

Predation by large carnivores is considered a major determinant in the demographics of ungulate popula- tions (Mech and Peterson 2003). It has been the subject of much research, and a short list of relevant citations here would inevitably be incomplete. Instead, this discussion will be limited to what is known about predation on Bighorn Sheep in Alberta.

Cougar Predation. At two localities, telemetry studies revealed that individual Cougars were having a major impact on small, isolated populations of sheep (Festa-Bianchet et al. 2006). The declines were halted after the death of these individual Cougars. However, in most years of their long-term study, FestaBianchet et al. (2006) reported no Cougar predation on sheep. Apparently, these ambush predators preyed mostly on deer (Ross and Jalkotzy 1992). This may well have been the case in the current study area.

During this study, Cougars were spotted three times on the Canyon slope and three times on the Ram Pasture, where they were seen feeding on the carcasses of sheep. Two of these might have been casualties of the railway that runs by the Ram Pasture. In only one case it appeared that the sheep, a mature ram, had actually been killed by the Cougar.

Wolf Predation. During this study only two mature rams are known to have been killed by Wolves, which were observed feeding on their prey. The rarity of these predation events was all the more surprising considering the high Wolf presence. The Ram Pasture was on a well-used Wolf travel route, and there appeared to be an obvious connection between sheep behaviour and Wolf visits. If all of the rams were standing on or close to the cliff, tracks in snow often revealed that Wolves had recently passed by. Conversely, if the 
Wolves had not been there for some time, the ram band would be grazing well away from the cliff on the higher slopes or even in adjacent woods (Dekker 2002). Bighorn Sheep have excellent eyesight and they are very alert to canids (Geist 1971). At Sheep River in southern Alberta, where Wolves are rare, sheep often forage in the woods (K. Ruckstuhl, personal communication). However, in localities where predators are common, sheep tend to frequent open terrain. Based on this study, predation rates on rams appear to be low. In most years, ram band numbers stayed the same from mid-February to the end of March.

Although Bighorn Sheep are vulnerable to ambush hunters like the Cougar, Festa-Bianchet et al. (2006) postulated that the anti-predator strategies Bighorn Sheep use are effective against cursorial predators such as Wolves. The above researchers did not present evidence or cite supportive publications. It appears that first-hand information on Wolf-bighorn interaction is rare, not only because most of North America's bighorn habitat lies outside the current range of Wolves, but also because their interactions are seldom witnessed. Even in Jasper National Park, where both species are common, there are very few observations of Wolves attacking sheep (Jasper National Park warden Wes Bradford, personal communication). Following are two Wolf-sheep interactions recorded in recent times.

In October 1990, a lone Wolf was seen and photographed in close pursuit of several ewes and lambs on the steep road escarpment above Medicine Lake (see photo in Dekker 1997: 107). The Wolf failed to catch a sheep and fell partway down the rocky slope, but did not appear to have injured itself (Jasper National Park biologist Ward Hughson, personal communication).

During this study, on 30 March 2007, a band of 26 ewes, yearlings, and lambs standing on the Canyon hillside were looking down at a Wolf walking along the cliff top some $80 \mathrm{~m}$ below the sheep. Suddenly, the Wolf sprinted up the steep slope. The band reacted by splitting into two groups, and half a dozen sheep ran downhill, bypassing the predator. The Wolf turned and sprang down after the fleeing sheep, but in vain. After three similar assaults, the entire band had managed to bypass the attacker and reach the safety of the canyon cliffs.

Cowan (1947) elaborated on the apparent ability of Bighorn Sheep to avoid Wolves. His list of 118 ungulates killed by Wolves in Jasper National Park and Banff National Park contained only 10 bighorns (9\%), and the percentage of sheep in his sample of Wolf scats $(n=358)$ collected by park wardens was $7 \%$. Thirty years later, Carbyn (1975) reported less than $10 \%$ sheep hair in his sample of Wolf scats from Jasper National Park, and he found no sheep kills at all by snow-tracking Wolf packs. Similarly, there were no sheep in a sample of 53 ungulates killed by Wolves in Jasper National Park from 1999 to 2001, and there were only 4 sheep in 176 Wolf kills found in Banff National Park between 2000 and 2005 (Banff National Park biologist J. Whittington, personal communication). These very low percentages suggest that Wolves kill few sheep compared to other hoofed mammals, all the more revealing in view of the fact that the bighorn is the most numerous ungulate in both Jasper National Park and Banff National Park.

Holroyd and VanTighem (1983) also noted the low incidence of bighorns in the diet of Wolves in Jasper National Park, although they cited several cases where sheep away from steep escape terrain had been surprised by Wolves. Sheep may be hunted relatively more frequently in habitats where other ungulates are scarce, for instance, in the narrow valley of the Fiddle River (Jasper National Park warden Greg Slatter, personal communication) or in alpine regions. In 19841985, provincial researchers flying helicopter surveys observed Wolves chasing sheep above the tree line on the eastern boundary of Jasper National Park (Schmidt and Gunson 1985).

\section{Coyote Predation.}

The most dangerous predator of sheep is possibly the Coyote. More common than either Cougar or Wolf, it may also be more agile in the kind of rough terrain that sheep inhabit. Holroyd and VanTighem (1983) cited several instances in which Coyotes were observed killing Bighorn Sheep. In this study, a Coyote was seen on a freshly killed ewe lying on the river ice below the Canyon cliffs (B. Genereux, personal communication). Elsewhere, on the opposite side of the Athabasca valley, a Coyote killed two lambs within 20 minutes (Dekker 1986).

The decline in Coyotes in the study area, based on sightings per day, was not limited to the last five years, but extended over the entire study period. The probable cause is hostile interaction with Wolves, which are known to kill Coyotes (Ballard et al. 2003). However, the decline accelerated significantly $(t=4.1$, $P<0.001$ ) between 2001 and 2006, suggesting that the drought was having an additional negative impact on Coyotes, possibly related to a decrease in small rodent prey. During the period 2001-2010, Red Foxes, Vulpes vulpes, also became increasingly rare, as indicated by scarcity of tracks.

\section{Range Deterioration and Drought}

The most obvious and significant negative factor affecting the sheep on the Ram Pasture was the decline in the quality of the forage due to the spread of a noxious weed commonly called Russian Thistle or Tumble Weed. The problem was first identified in 1993, but the infestation must have started earlier. By 1994, some $20-40 \%$ of the slopes at Ram Pasture were covered with this prolific annual (Dekker 1995*). When young, the seedlings are soft and green and can be eaten by herbivores, but over summer the stems become 
brittle and the leaves harden into thorns that are unpalatable. On livestock ranges, this noxious weed is considered an indicator of overgrazing (D. Johnson, Natural Resources Canada, personal communication). On the Ram Pasture, the thistles probably invaded when the range was frequented by both rams and ewes. Interestingly, the departure of the local ewe band coincided with the thistle outbreak (Figure 2). By 2006, after grazing pressure had lessened, the thistles were again replaced by grasses, followed by a slight increase in the number of wintering rams (Table 1).

The thistles did not spread to the Canyon site. However, in 2001, an equally if not more serious negative factor became apparent: drought. The annual precipitation totals for the period 2001-2004 were $414 \mathrm{~mm}$ in $2001,417 \mathrm{~mm}$ in 2002, $470 \mathrm{~mm}$ in 2003, and $419 \mathrm{~mm}$ in 2004, well below the 35 -year mean of $569 \mathrm{~mm}$. During these drought years, while the band size declined significantly, the denuded Canyon slopes turned to dust. Scraping for plant roots, the sheep aggravated the problem. Eventually, the ewes all but abandoned the eroding slopes. On nine visits between 2001 and 2010, I spotted no sheep on the Canyon site. Prior to 2001, they had been present every day.

Due to their southeasterly aspect, the Ram Pasture and the Canyon were severely affected by the lack of rain, but the montane meadows were drying up as well. Groundcover withered, with bare soil showing between the vegetation. The plant succession during early summer included drought-resistant and unpalatable species such as Pasture Sage (Artemisia frigida) and Owl Clover (Orthocarpus luteus), which is more typical of semi-arid prairie habitats (Cormack 1977).

\section{Conclusion}

In summary, it is remarkable that the sheep numbers were stable from 1981 to 2001 in spite of the presence of predators. This finding supports the hypothesis, advanced by Festa-Bianchet et al. (2006), that predator-prey equilibria can exist at large geographical and temporal scales. The low lamb:ewe ratios were apparently adequate to maintain the population, at least prior to the drought years. Similarly, low recruitment levels in British Columbia (24 juveniles to $100 \mathrm{fe}$ males) were reportedly sufficient to balance predation losses in a multiple ungulate prey system that included Thinhorn Sheep (Ovis dalli stonei) (Bergerud and Elliott 1998).

What is unknown is whether the localized drop in sheep numbers reported here is indicative of a real decline in the mega population of Jasper National Park bighorns. Ewes abandoning the study area might have wintered elsewhere. On the Canyon, bands were often observed to come and go. Some left in a northwesterly direction following the high banks of the Snake Indian River; others moved out of sight along the Athabasca escarpment. Overall stability of the larger population in Jasper National Park is suggested by the stability of the numbers of the ram band, which changed rela- tively little over the 30 years. Unfortunately, nothing is known about the greater territory of these rams and the distances they travel in order to meet up on their traditional winter range at Ram Pasture. Research is needed to see whether they and the ewe bands will again increase if annual precipitation totals return to or exceed the long-term mean and lead to recovery of the damaged Canyon slopes. At the termination of this long-term study, the prospects seemed bleak. In 2008 and 2009, annual precipitation totals for Jasper National Park were 306 and $194 \mathrm{~mm}$, respectively, the lowest recorded since 1971.

\section{Acknowledgements}

I thank Jasper National Park wardens W. Bradford and G. Slatter for logistical support and for sharing their wildlife sightings. P. DeMulder and B. Genereux were frequent field companions. Relevant literature on sheep dynamics was made available by K. Ruckstuhl, M. Festa-Bianchet, and J. Jorgenson. Parks Canada biologist J. Whittington kindly provided data on Wolf kills in Jasper National Park and Banff National Park. M. Dekker tested some data sets for statistical significance. M. Out drafted the graphs. K. Ruckstuhl, W. Wishart, and one anonymous referee made helpful comments on an earlier draft of the manuscript. During the first 10 years, I received partial funding from World Wildlife Fund (Canada), Canadian Wolf Defenders, and the Alberta Recreation, Parks, and Wildlife Foundation. After 1992, the study was funded privately by the author.

Documents Cited (marked * in text)

Dekker, D. 1995. Russian Thistle-its occurrence and local infestations in the Devona district of Jasper National Park. Report for Parks Canada.

Dekker, D. 2001. Two decades of wildlife investigations at Devona, Jasper National Park, 1981-2001. Report for Parks Canada.

Dekker, D. 2008. Wildlife investigations at Devona, JNP, for the winters of 2001-2006, with comparisons to 1981-2001. Report for Parks Canada.

\section{Literature Cited}

Ballard, W. B. , L. N. Carbyn, and D. W. Smith. 2003. Wolf interactions with non-prey. Pages 259-271 in Wolves, behavior, ecology, and conservation. Edited by L. D. Mech and L. Boitani. University of Chicago Press, Chicago, Illinois.

Bergerud, A. T., and J. P. Elliott. 1998. Wolf predation in a multiple ungulate system in northern British Columbia. Canadian Journal of Zoology 76: 1551-1569.

Carbyn, L. N. 1975. Wolf predation and behavioural interactions with elk and other ungulates in an area of high prey diversity. Unpublished Ph.D. dissertation, University of Toronto, Toronto, Ontario, Canada.

Cormack, R. G. H. 1977. Wildflowers of Alberta. Hurtig Publishers, Edmonton, Alberta, Canada.

Cowan, I. McT. 1947. The timber wolf in the Rocky Mountain national parks of Canada. Canadian Journal of Research 25: 139-174. 
Dekker, D. 1986. Coyote preys on two bighorn lambs in Jasper National Park, Alberta. Canadian Field-Naturalist 100: 272-272.

Dekker, D. 1989. Population fluctuations and spatial relationships among wolves, coyotes, and red foxes in Jasper National Park, Alberta. Canadian Field-Naturalist 103: 261264.

Dekker, D. 1997. Wolves of the Rocky Mountains-from Jasper to Yellowstone. Hancock House Publishers, Surrey, British Columbia, Canada, and Blaine, Washington.

Dekker, D. 1998. Pack size and colour morphs of one wolf pack in Jasper National Park, Alberta, 1979-1998. Canadian Field-Naturalist 112: 709-710.

Dekker, D. 2002. The bighorn's dilemma. Pages 156-163 in Wildlife adventures in the Canadian west. Rocky Mountain Books, Calgary, Alberta, Canada.

Dekker, D., W. Bradford, and J. R. Gunson. 1995. Elk and wolves in Jasper National Park, Alberta. From historical times to 1992. Pages 85-94 in Ecology and conservation of wolves in a changing world. Edited by L. N. Carbyn, S. H. Fritts, and D. R. Seips. Canadian Circumpolar Institute, Edmonton, Alberta, Canada. Occasional Publication Number 35.

Festa-Bianchet, M. 1991. The social system of bighorn sheep - grouping patterns, kinship, and female dominance rank. Animal Behaviour 42: 71-82.

Festa-Bianchet, M., J. T. Jorgenson, W. J. King, K. G. Smith, and W. D. Wishart. 1996. The development of sexual dimorphism: seasonal and lifetime mass changes of bighorn sheep. Canadian Journal of Zoology 76: 330-342.

Festa-Bianchet, M., T. Coulson, J. M. Gaillard, J. T. Hogg, and F. Pelletier. 2006. Stochastic predation events and population persistence in bighorn sheep. Proceedings of the Royal Society 273: 1537-1543.

Geist, V. 1971. Mountain Sheep; a study in behaviour and evolution. University of Chicago Press, Chicago, Illinois.

Gunson, J. R. 1992. Historical and present management of wolves in Alberta. Wildlife Society Bulletin 20: 330-339.

Holroyd, G. L., and K. J. VanTighem. 1983. Ecological (biophysical) land classification of Banff and Jasper National Parks. Volume III. The Wildlife Inventory. Canadian Wildlife Service, Edmonton, Alberta, Canada.

Jensen, M. N. 2004. Climate warming shakes up species. BioScience 54: 722-729.

Jorgenson, J. T., W. Festa-Bianchet, M. Lucherini, and W. D. Wishart. 1993. Effects of body size, population density, and maternal characteristics on age of first reproduction in bighorn ewes. Canadian Journal of Zoology 71: 2509-2517.

Jorgenson, J. T., M. Festa-Bianchet, J. M. Gaillard, and W. D. Wishart. 1997. Effects of age, sex, disease, and density on survival of bighorn sheep. Ecology 78: 10191032.
Mech, L. D., and R. O. Peterson. 2003. Wolf-prey relations. Pages 131-157 in Wolves, behavior, ecology, and conservation. Edited by L. D. Mech and L. Boitani. University of Chicago Press, Chicago, Illinois.

Murie, A. 1944. The wolves of Mount McKinley. U.S. Department of the Interior, Fauna Series Number 5.

Portier, C., M. Festa-Bianchet, J. M. Gaillard, J. Y. Jorgenson, and N. G. Yoccoz. 1998. Effects of density and weather on survival of bighorn sheep lambs. Journal of Zoology 245: 271-278.

Rominger, E. M., H. A. Whitlaw, D. Weybright, W. C. Dunn, and W. Ballard. 2004. The influence of mountain lion predation on bighorn sheep translocations. Journal of Wildlife Management 68: 993-999.

Ross, P. I., and M. G. Jalkotzy. 1992. Characteristics of a hunted population of cougars in southwestern Alberta. Journal of Wildlife Management 56: 417-426.

Ross, P. I., M. G. Jalkotzy, and M. Festa-Bianchet. 1997. Cougar predation on bighorn sheep in southwestern Alberta during winter. Canadian Journal of Zoology 74: 771-775.

Ruckstuhl, K. E. 1998. Foraging behaviour and sexual segregation in bighorn sheep. Animal Behaviour 56: 99-108.

Ruckstuhl, K. E., and M. Festa-Bianchet. 2001. Group choice by subadult bighorn rams: trade-offs between foraging efficiency and predator avoidance. Ethology 107: 161-172.

Schmidly, D. J. 2005. What it means to be a naturalist and the future of natural history at American universities. Journal of Mammalogy 86: 449-456.

Schmidt , K. P., and J. R. Gunson. 1985. Evaluation of wolf-ungulate predation near Nordegg, Alberta. Second year progress report. Alberta Fish and Wildlife Division, Canada.

Soper, J. D. 1970. The mammals of Jasper National Park, Alberta. Canadian Wildlife Service Report Series 10.

Stelfox, J. G. 1971. Bighorn sheep of the Canadian Rockies: a history 1800-1970. Canadian Field-Naturalist 85: 101122.

Stelfox, J. G. 1978. Seasonal distribution of Rocky Mountain bighorn sheep in Canadian national parks, 1966-1972. Report for Parks Canada, Canadian Wildlife Service.

Wehausen, J. D. 1996. Effects of mountain lion predation on bighorn sheep in the Sierra Nevada and Granite Mountains of California. Wildlife Society Bulletin 24: 471-479.

Wishart, W. 1999. A working hypothesis for Rocky Mountain bighorn sheep management. In Transactions of the $2^{\text {nd }}$ North American Wild Sheep Conference, Reno, Nevada.

Wishart, W., B. MacCallum, and J. Jorgenson. 1998. Lessons learned from rates of increase in bighorn herds. Pages 126-132 in Proceedings of the Eleventh Biennial Symposium of the Northern Wild Sheep and Goat Council, April 16-20, 1998, Whitefish, Montana.

Received 21 April 2009

Accepted 5 April 2010 